\title{
A importância do trabalho do psicólogo escolar aos docentes em escolas públicas
}

\author{
Importance of the work of psychologist with instructors in public schools
}

Marlúcia Silva Garcia Antunes Costa - Colégio Batista Mineiro - marluciagarcia@yahoo.com.br Nathália Dornelas Barbosa - Universidade Federal de Minas Gerais - nathaliadb@hotmail.com Patricia Rossi Carraro - Centro Universitário de Rio Preto - patricia.carraro@sebsa.com.br

\begin{abstract}
Resumo: Diante dos relatos cada vez mais frequentes de professores agredidos, afastados de seu ofício por estresse, fadiga, doenças psicossomáticas ou simplesmente por insatisfação e desmotivação, faz-se necessário lançar um olhar mais atento sobre a docência. Considera-se que o professor, em sua jornada de trabalho, precisa de apoio, suporte e orientação da área da psicologia escolar que favoreçam a melhoria no ensino-aprendizagem e na relação professor-aluno. Este artigo tem como objetivo mostrar a importância do trabalho do psicólogo escolar aos docentes, que vivenciam situações cada vez mais frequentes de violência na escola e de desgaste emocional e físico. Como instrumento metodológico foi realizado um levantamento bibliográfico da produção científica acerca do papel e da atuação do psicólogo escolar, do trabalho docente, da violência escolar e da síndrome de Burnout, por meio dos sistemas informatizados de busca Scientific Electronic Library Online (SciELO) e Periódicos Eletrônicos de Psicologia (PePSIC). Pesquisaram-se, também, alguns livros sobre o trabalho do psicólogo escolar. Os resultados demonstraram que diante da violência no cotidiano das escolas, do estresse do professor e do descaso de modo geral com a profissão docente, o psicólogo deve ser inserido no ambiente escolar de forma sistemática e urgente, com vistas a melhores condições de trabalho aos professores e maior valorização da classe e, por conseguinte, da educação de um modo geral.
\end{abstract}

Palavras-chave: docente, psicologia, violência, estresse, escola pública.

\begin{abstract}
Front of recent increasingly reports of teachers aggressed, removed from their work because of stress, fatigue, psychosomatic illness or simply by dissatisfaction and demotivation, it was made necessary to look carefully at teaching. It is considered that teachers, in their work-day, need support, aid and guidance from psychology area of school favoring the improvement of teaching-learning and teacher-student relationship. This paper intends to show the importance of school psychologists' work with the teaching staff that lives more and more situations of violence at school and physical and emotional damage. It was made, as methodological instrument, a bibliographic research into scientific production on Scientific Electronic Library Online (SciELO) e Periódicos Eletrônicos de Psicologia (PePSIC) about the paper and operation of school psychologist, teaching work, violence at school and Burnout's syndrome. It was researched some books about the work of the school psychologist too. The results shows that against the violence at school, the stress of the teacher and general neglect with teaching profession, the psychologist may systematically and urgently enter in the environment of school, aiming to get better work conditions for teachers, more appreciation of the class and, consequently, of the education in a general view.
\end{abstract}

Keywords: teaching, psychology, violence; stress; public school.

$\mathrm{O}^{\mathrm{s}}$ docente vive frequentemente situações de conflito na escola com as quais não está conseguindo lidar. A violência, o contato com o mundo das drogas, a carência socioeconômica dos alunos são questões muito graves e excessivamente complexas para serem resolvidas em sala de aula. Porém, não há como separar a realidade dos alunos das situações de aprendizagem, mas é possível oferecer aos professores um maior preparo para lidar com tais questões.
Por causa das condições precárias de trabalho, deparamos com professores que desenvolvem diversos problemas, como síndrome do pânico, síndrome de Burnout, estresse, doenças psicossomáticas, desmotivação, insatisfação, sofrimento psíquico, depressão e outros.

Segundo Fontana (1998, p. 408), "por sua natureza, a profissão do professor é uma ocupação estressante". Portanto, ao lidar com situações adversas, ele se 
sente despreparado, impotente e, por assim dizer, desestimulado. Ainda de acordo com Fontana (1998, p. 408), "os professores encontram uma gama constante de pressões das crianças, dos colegas, dos pais, de políticos e administradores, muitas delas conflitantes e impossíveis de atender". Os professores precisam manter constantemente o controle sobre a sala. Este é um desafio constante. Eles não possuem limites claros de horário de trabalho. Boa parte do seu trabalho é levado para casa, o que torna difícil desligar-se no fim do dia, tendo em algumas vezes que trabalhar até tarde. Estão expostos a críticas de inspetores, pais, diretores, meios de comunicação e políticos. Não dispõem de recursos e oportunidades suficientes para capacitação frequente e ampla de seus conhecimentos.

Diante desse contexto, este artigo tem como objetivo realizar uma pesquisa na busca do conhecimento produzido acerca do trabalho do psicólogo escolar com os docentes, no que diz respeito aos aspectos de violência escolar e da síndrome de Burnout. Pretende-se conhecer os benefícios da intervenção desse profissional e contribuir com uma reflexão sobre a realidade educacional brasileira. Como instrumento metodológico foi realizado um levantamento bibliográfico da produção científica acerca das relações entre o papel e a atuação do psicólogo escolar, acerca do trabalho docente, da violência escolar, e da síndrome de Burnout, por meio dos sistemas informatizados de busca Scientific Electronic Library Online (SciELO) e Periódicos Eletrônicos de Psicologia (PePSIC). Os artigos pesquisados compreenderam o período de 2003 a 2012, com o seguinte descritor: psicólogo escolar, o trabalho docente, violência escolar e síndrome de Burnout. Pesquisaram-se, também, alguns livros sobre o trabalho do psicólogo escolar.

Muitas vezes, os professores não sabem como lidar com a dura realidade de seus alunos e sentem-se incapazes de promover a transformação dessa realidade por meio da educação. Assim sendo, o professor muitas vezes prefere ignorar os problemas e calar a violência, o sofrimento e a angústia, e, dessa forma, o papel transformador que os professores podem desempenhar na vida desses jovens é negligenciado.

Um grande desafio a ser vencido no contexto educacional é a implantação de uma gestão democrática, que implica a participação das pessoas nos processos decisórios, tendo em vista a construção e o exercício da autonomia em um contexto de relações e interdependências, no qual nem sempre escola e comunidade se assemelham, mas podem produzir consensos e parcerias. Isso contraria o ponto levantado por Anser, Joly e Vendramini (2003) em que se apontam apenas duas direções que os docentes devem tomar em suas aulas: a imposição de maneiras e conhecimentos a alunos que se negam a aceitá-los ou ceder e deixá-los à deriva.
Uma gestão mais integradora e participativa pode parecer impossível e deixar os professores oprimidos entre a necessidade de cumprir os programas e diretrizes e as demandas socioeducacionais locais.

Acreditando ser esse problema consequência de uma dificuldade de relacionamento e de compreensão do outro, sugere-se a inserção da figura do psicólogo escolar como mediador e solucionador de conflitos na escola. Este poderá auxiliar o docente em suas dificuldades em interagir com seus alunos e com a comunidade escolar, promovendo uma relação mais saudável, e, a partir dos conhecimentos da Psicologia e de suas experiências na área escolar, ele poderia ainda realizar o apoio aos problemas vivenciados pelo professor e ajudá-lo a transformar angústias e frustrações em compreensão e mudanças em sua prática. Como resultado, acredita-se que haveria redução do absenteísmo no trabalho, do adoecimento, de casos de estresse e de abandono do emprego.

Visando à busca de um olhar mais focado na qualidade de vida e bem-estar do professor, e baseado em pesquisa bibliográfica, este estudo intenta investigar as dificuldades, as possíveis soluções e a contribuição que a figura do psicólogo teria para amenizar o sofrimento dos docentes. Certamente essa não é uma questão simples, pois vários são os aspectos que extrapolam o contexto escolar; entretanto, há uma necessidade urgente de buscar soluções, e o psicólogo poderá representar um suporte profissional para melhorar as condições de trabalho do professor.

\section{O APOIO DO PSICÓLOGO ESCOLAR AOS DOCENTES}

É de conhecimento geral a inexistência de políticas públicas que promovam suporte médico ou psicológico ao docente nas escolas públicas.

Espera-se do professor um preparo, capacitação e estímulo para exercer sua profissão e a competência para resolver uma diversidade de problemas que chegam à sala de aula, porém não há suporte técnico, pedagógico e psicológico para o enfrentamento das mais diversas situações, sejam elas de aprendizado ou até mesmo de violência por parte dos alunos para com o professor.

Segundo Kupfer (1997 apud Anser, Joly e Vendramini, 2003), o docente no Brasil não possui mais incentivos sociais para exercer o seu mandato e não encontra o devido respaldo institucional ou comunitário, sentindo-se, assim, profundamente desamparado para realizar o seu trabalho. Nesse sentido, o professor deixa passar sua fragilidade, insegurança, medos e angústias e não assume o seu papel de educador. Justifica possíveis falhas no trabalho 
diário com os alunos responsabilizando o sistema por uma administração falida e corrupta.

Entende-se que o papel do psicólogo na escola poderá trazer ao professor uma visão mais otimista da realidade e resgatar o seu bom desempenho mantendo sua influência positiva no aprendizado do aluno e no ambiente escolar como um todo. O psicólogo escolar poderá reequilibrar a dinâmica escolar e criar uma rede de apoio e responsabilidades de modo a dar mais suporte e autonomia aos professores. O professor deve ser capaz de valorizar o seu trabalho e entender a responsabilidade dele em relação à sociedade, não como uma carga pesada, mas como uma forma de transformar a dura realidade dos alunos, de famílias e da comunidade escolar, tendo a clareza de que nada pode ser feito isoladamente.

Um acompanhamento sistemático de um psicólogo na escola daria, ao docente e aos demais membros administrativos e pedagógicos, maiores condições de enfrentar o cenário caótico de estresse e violência do cotidiano. Quando um professor tem que atuar em funções burocráticas e administrativas, por exemplo, que nada tenham a ver com sua formação docente, há um desvio funcional e o comprometimento tanto do trabalho pedagógico quanto da administração. As funções devem ser integradas e não misturadas. Esse engano, muitas vezes, gera descontentamento e desgaste. Justamente por ter uma visão integral e sistêmica, o psicólogo escolar contribui para impedir a sobrecarga laboral e o acúmulo de funções por parte dos membros da equipe.

Portanto, o papel do psicólogo escolar deve ser ampliado para além do atendimento às dificuldades de relacionamento e queixas escolares dos alunos, e estender-se à instituição escolar como um todo (equipe técnico-pedagógica, familiares, comunidade), trabalhando a integralização dos indivíduos e procurando entender a dinâmica que o cerca, como forma de detectar as dificuldades e assim buscar soluções, não problematizando todo o contexto escolar a partir de dados extraídos somente dos alunos, mas das deficiências internas da instituição e das dificuldades dos docentes, inerentes aos aspectos psicológicos, salariais, condições de trabalho e satisfação no âmbito da sua profissão.

Para Giongo e Oliveira-Menegotto (2010), há uma concepção inacabada e um não entendimento acerca do papel do psicólogo escolar e sua real função. O esclarecimento dessa especificidade da psicologia bem como a necessidade de se ter efetivamente esse profissional no quadro de funcionários das escolas públicas poderia representar um ganho sem precedente para a educação brasileira, tão carente de investimentos efetivos para o professor.
O fato de o professor não conhecer o papel do psicólogo escolar nos remete a pensar que esse assunto até então não havia sido problematizado junto à equipe ou que o psicólogo até então não havia feito parte da experiência do professor. Sendo assim, como o professor pode construir um conceito positivo sobre a presença do psicólogo na escola se este não se faz presente ou se não existem espaços na instituição para que o assunto seja problematizado? (GIONGO; OLIVEIRA-MENEGOTTO, 2010, p. 866).

É preciso que o psicólogo, ao fazer parte do contexto escolar, deixe claros seus espaços de atuação, suas funções e papéis, pois os educadores ainda não tem conhecimento da importância da sua presença na escola, ou aqueles que conhecem consideram o conteúdo da psicologia pouco relevante.

Nesse sentido, faz-se necessário, nesse momento esclarecer a prática do psicólogo em contextos escolares, segundo a visão de alguns pesquisadores da área.

De acordo com Vectore e Maimoni (2007, p. 135), a atuação do psicólogo escolar esteve fundamentada, inicialmente, a um modelo clínico, remediativo (termo médico utilizado como oposto ao de prevenção), "marcada pela questão do diagnóstico dos problemas de aprendizagem e suas possibilidades de superação". Contudo, ao longo dos tempos, várias mudanças de ordem social, política, filosófica e educacional configuraram a história da Psicologia Escolar e possibilitaram alterações significativas nas funções do psicólogo.

Martínez (2007) aponta-nos que o psicólogo escolar pode trabalhar com a formação e orientação a professores, orientação a alunos e pais, orientação sexual, elaboração e coordenação de projetos educativos específicos (por exemplo, em relação à violência, uso de drogas, relações interpessoais e outros), avaliação e atendimento ou encaminhamento de alunos com queixas escolares.

A autora ainda nos acrescenta que existem outras funções que o psicólogo pode exercer, consideradas emergentes, como, por exemplo:

\footnotetext{
assessoramento para elaboração, implementação e avaliação da proposta pedagógica da escola, assessoria e participação no processo de seleção dos membros da equipe pedagógica e de avaliação dos resultados do trabalho docente, contribuição para a formação técnica e para a coesão da equipe de direção pedagógica, realização da análise institucional e muito especialmente dos aspectos da subjetividade social da instituição escolar, com o objetivo de delinear estratégias de trabalho favorecedoras de mudanças necessárias a nível institucional, coordenação de disciplinas e oficinas direcionadas ao desenvolvimento integral dos alunos, caracterização da população estudantil com o objetivo de melhorar o processo educativo e facilitar de forma crítica, reflexiva e criativa a implementação das políticas públicas (MARTíNEZ 2007, p.117).
} 
Neves (2011) acrescenta-nos que, devido à demanda do contexto escolar, o psicólogo escolar deve estar pronto para ouvir os que fazem parte da escola, compreendendo suas histórias, suas especificidades e, a partir daí, trabalhar em equipe, no sentido de rever posições cristalizadas, de proporcionar reflexões críticas que partam de uma compreensão não alienada da situação de nossas escolas.

É importante ressaltar que o próprio Estado já reconheceu que as condições de trabalho do docente são patogênicas; não justifica que não seja instituído um psicólogo escolar para atuar com os professores da rede pública.

As leis brasileiras de auxílio ao trabalhador já contemplam a Síndrome de Burnout. No Anexo II - que trata dos Agentes Patogênicos causadores de Doenças Profissionais - do Decreto n³048/99 de 6 de maio de 1996 - que dispõe sobre a Regulamentação da Previdência Social -, conforme previsto no Art.20 da Lei n8.213/91, ao se referir aos transtornos mentais e do comportamento relacionado com o trabalho (Grupo V da CID-10), o inciso XII aponta a Sensação de Estar Acabado (Síndrome de Burn-Out, Síndrome do Esgotamento Profissional) (Z73.0) (MINISTÉRIO DA SAÚDE apud CARLOTTO, 2008).

Nessa perspectiva, é urgente a necessidade de acompanhar os professores em seu contexto de trabalho, como uma medida preventiva, já que vários estudos e pesquisas têm apontado para um quadro de apatia e/ ou repulsa à profissão, devido às ações insuficientes para melhoria de trabalho dos docentes.

A partir das ideias e questões apontadas anteriormente, é importante destacar que existe um Projeto de Lei (PL) 3688/2000, que prevê a inserção de psicólogos e assistentes sociais nas escolas.

O PL prevê que psicólogos e assistentes sociais atuem nas escolas como profissionais parceiros dos gestores, professores, outros trabalhadores e membros da comunidade escolar, trabalhando na implantação de projetos pedagógicos, pela melhoria da qualidade do processo de ensino-aprendizagem e na mediação das relações sociais e institucionais (CONSELHO REGIONAL DE PSICOLOGIA, 2013).

Segundo o Conselho Regional de Psicologia (2013), o projeto de lei foi apresentado em 2000, na Câmara dos Deputados. Foi aprovado em 2007 e encaminhado ao Senado Federal. Na Comissão de Seguridade Social e Família, o projeto foi aprovado em 2012. Agora o PL será apreciado pela Comissão de Constituição, Justiça e Cidadania. Na sequência, irá para o Plenário da Casa, depois para a sanção da presidenta Dilma Rousseff.

Nesse sentido, Guzzo, Mezzalira e Moreira (2012) realizaram uma pesquisa que visou aprofundar um debate que vem crescendo dentre os psicólogos brasileiros a respeito da sua inserção nas políticas públicas educacionais. Em 2008, o Conselho Federal de Psicologia conduziu um amplo debate nacional sobre essa questão com os diferentes conselhos regionais. Os debates e as discussões resultantes desses encontros foram sistematizados e apresentados no Seminário Nacional do Ano da Educação em 2009. Com base nos relatórios apresentados, esse estudo organiza o que foi registrado, focalizando a identificação de problemas e perspectivas necessárias à inserção do profissional nos processos de formular e avaliar as políticas educacionais, bem como de trabalhar no sistema público. Os registros foram organizados em três categorias: psicologia escolar e educacional - formação e pesquisa em políticas públicas; psicólogo escolar e educacional - inserção e participação nas políticas públicas educacionais; e inserção do psicólogo no contexto público educacional - dilemas e perspectivas. Conclui-se que os resultados encontrados nessa pesquisa apontaram alguns aspectos que poderiam estar dificultando a entrada do psicólogo na rede pública de educação, bem como possibilitaram uma reflexão sobre alguns encaminhamentos direcionados para o enfrentamento dessa situação. A formação do psicólogo, desprovida de discussões políticas e de práticas direcionadas a sua participação na construção da profissão, tem se configurado como um empecilho. Por isso, torna-se de fundamental importância haver uma mudança na grade curricular dos cursos de graduação, com vistas à contemplação dessas questões. A inserção do profissional de Psicologia Escolar e Educacional nos espaços públicos, como fóruns e audiências que discutam políticas públicas educacionais, torna-se imprescindível para efetivar a sua entrada no contexto educativo. Ressalta-se que a luta pela sua admissão como funcionário da escola perpassa, obrigatoriamente, pela exigência de definições de sua atuação nos editais, evitando a alocação de psicólogos de outras secretarias para agir na escola. Além disso, torna-se necessário ter um olhar crítico na escolha dos referenciais teóricos que serão cobrados nos concursos. Isso porque o estudo de teorias que não contemplam uma visão contextualizada dos alunos fortalece uma prática clínica e remediativa do psicólogo no contexto escolar.

A partir das informações acima, pode-se constatar que, apesar da demora quanto aos trâmites legais e ao aguardo da aprovação final, existe uma preocupação por parte do Conselho de Psicologia no tocante à inserção de psicólogos na rede a partir do referido projeto. 


\section{O PROFESSOR QUE VIVE NO LIMITE}

O cotidiano da escola pública brasileira, especialmente as que estão localizadas nas periferias, onde os alunos convivem com toda sorte de diferenças sociais e violências, é permeado por situações-problema que atingem toda a comunidade escolar e principalmente o professor, uma vez que na escola é ele quem lida com os alunos na maior parte do tempo.

Os professores vivem um sentimento de insegurança generalizado pela falta de segurança interna nas escolas, que espelha a criminalidade urbana crescente (CAMPOS et al., 2005).

Assim, muitos professores distanciam-se da realidade dos seus alunos, como forma de se autoproteger. Esquivam-se de sua responsabilidade, agravando as desigualdades, culminados em conformismo, em ceticismo e em aceitação fatalista da realidade (GUZZO, 2005).

Por sua vez, a escola não assiste o professor de maneira que ele se sinta seguro e preparado para exercer seu papel de educador, de forma completa e eficiente.

Ainda segundo Guzzo (2005)

Uma escola que não se posiciona, que não reage, que não desperta para a importância como espaço de libertação e conscientização, de revolução e emancipação, de crescimento e de vida - uma escola amordaçada que se imobiliza diante da realidade sem conseguir buscar caminhos para sua superação (p. 20).

Para Anser, Joly e Vendramini (2003), "a escola, como instituição que faz parte da sociedade, sofre os reflexos dos fatores de violência externos que têm gerado conflitos manifestados dentro da sala de aula, comprometendo o aprendizado e as relações interpessoais". Dessa forma, o enfrentamento dos problemas de violência, aliado à falta de estrutura da instituição, no sentido de prevenir todas as formas de abusos contra os atores nas escolas - sejam eles alunos, funcionários, professores -, aliado aos salários irrisórios, condições precárias de trabalho, falta de estímulo na profissão, dentre outras situações, leva o educador a viver no limite de suas forças físicas, psicológicas e profissionais.

Em decorrência, o mais comum é se ouvirem queixas de que os mestres assumem postura acuada, medrosa, invariavelmente de defesa, culminando na acusação da família dos alunos e, por fim, na exclusão dos acusados - assim configurando um dos aspectos da violência que perpetrada pela escola recai sobre os estudantes (CAMPOS et al., 2005)
Os paradigmas comportamentais do professor, de 20 anos atrás até hoje, deparam-se com a tentativa de democratização da escolarização em uma realidade despreparada e desqualificada para lidar com os problemas psicossociais. Estes adentram as escolas, pois são resultados de um crescimento desordenado dos centros urbanos, que vivem perante uma violência decorrente da falta de perspectivas sociais igualitárias. Assim, os jovens, acuados pelo sistema, enfrentam situações de delinquência, agressões etc., atingindo de forma cruel e sistemática o interior dos educandários, visto que é o lugar onde acontece, ou - melhor dizendo - deveria acontecer a socialização dos sujeitos.

De acordo com Kupfer (1997 apud Anser, Joly e Vendramini, 2003), o professor deixou de ser representativo, não fala mais em nome de uma ordem transitória que o supera. Ele está jogado à sua imediata e trágica particularidade.

A pesquisa realizada por Carraro e Andrade (2011), cuja finalidade foi investigar as probabilidades e os contornos para a realização de grupos sociodramáticos reflexivos com docentes do ensino fundamental, relata que as ponderações grupais tornam-se ferramentas que estimulam o alargamento do pensamento e o desprendimento para afrontar o enredamento, as inseguranças e as injustiças na instituição escolar, bem como na sociedade. Os autores perceberam nas reuniões que os docentes enfrentavam angústias, ansiedades, bem como dificuldades de expor suas ideias.

O discurso dos professores mostrou que eles têm, uma visão negativa de si mesmos. Em alguns momentos, desmereciam-se ou desvalorizavam-se. Em algumas reuniões, ao falarem que os políticos, o Governo e a sociedade não os consideram, os professores pareciam ter incorporado este discurso. Os docentes usaram também o termo "reciclagem" para os cursos de capacitação que fazem na diretoria de ensino, indicando provavelmente que eles próprios desvalorizam a profissão (CARRARO; ANDRADE, 2011, p. 1338).

Segundo os autores ainda, o papel do psicólogo como coordenador de grupo sociodramático foi muito importante para que alguns dos professores compreendessem o significado desse tipo de atividade no contexto escolar, e apontaram a importância deste como um espaço para o desabafo, ou seja, como um momento para falar dos problemas, ouvir e aprender com o outro, trocar experiências e receber apoio diante das dificuldades apresentadas. Os participantes almejaram a continuidade do trabalho em grupo. 
De fato o trabalho de grupo revelou que para esses professores, sobrecarregados por uma realidade de trabalho "difícil", é de suma importância a promoção de ações capazes de "olhar" para as condições em que se realizam as práticas profissionais no dia a dia, bem como de estabelecer um espaço mais acolhedor, mais afetivo, mais envolvido com a formação do professor, do aluno e da equipe técnicopedagógica. Não se pode deixar de ressaltar que os relatos dos professores apontaram que esse trabalho representou um espaço muito importante para os participantes que se encontravam em momentos "muito difíceis", convivendo em um ambiente escolar bastante complexo. Por fim, acredita-se que os membros do grupo se beneficiaram, pois a angústia e o sofrimento que o funcionamento da escola gerou puderam ser "compartilhados" no grupo.

Dessa forma, excluir o psicólogo escolar desse contexto é deixar a escola à sua própria sorte, criando um abismo irreparável entre a educação e uma nação justa e preparada para o enfrentamento dos conflitos sociais. Deixar a sociedade perversa ditar um comportamento nocivo e violento dentro da escola é renegar a democracia e desvalorizar a educação, como agente de construção de sujeitos conhecedores de seus direitos e deveres.

Não significa, porém, que o psicólogo, ao ter e ao assumir um compromisso com as questões sociais, irá resolver todos os problemas, aflições e dilemas da instituição escolar e da sociedade, como muitas pessoas acreditam. Isso é uma ilusão. Sabe-se que a Psicologia, como uma área da ciências humanas, pode contribuir com técnicas, procedimentos e conhecimento científico adequados, com vistas a melhorias nas relações humanas, na prática docente, na formação do aluno e na inserção e participação da família na escola.

Portanto, faz-se necessário uma intervenção urgente do Estado, no sentido de garantir políticas públicas de segurança eficazes nas escolas, como forma de minimizar dramas cada vez mais comuns nas instituições educacionais, associados à violência, às agressões, às humilhações etc., bem como de garantir o apoio do psicólogo nesta tarefa de superação de conflitos.

\section{SÍNDROME de BURNOUT}

A Síndrome de Burnout é considerada por Harisson (1999 apud Carlotto, 2002) como uma modalidade de estresse de caráter persistente e diretamente relacionado às situações de trabalho, resultante da constante e repetitiva pressão emocional advinda de intenso envolvimento com pessoas por longos períodos de tempo.
Burn-out, no jargão popular inglês, refere-se a algo que deixou de funcionar por absoluta falta de energia. É uma metáfora para significar aquilo, ou aquele, que chegou ao seu limite e, por falta de energia, não tem mais condições de desempenho físico ou mental (BENEVIDES-PEREIRA apud TARNOWSKI; CARLOTTO, 2007).

Não raramente, os professores manifestam problemas de saúde que estão diretamente relacionados ao ofício docente e à interação com os alunos, com suas famílias e com outros funcionários do ambiente educacional.

A estrutura social e escolar do nosso país exige dos professores uma atuação que extrapola o ensino, tais como controle disciplinar dos alunos e serviços de secretária. Como os professores não foram preparados para isso, essas situações causam grande frustração e irritabilidade.

Além disso, a sociedade moderna tem apresentado uma dissolução dos papéis tradicionais, nos quais cabia à família a transmissão de valores, e aos professores apenas a educação formal. A ida massiva de pais e mães para o mercado de trabalho tem transferido para a escola, consequentemente para o professor, a função de realizar a educação de forma integral dos jovens (CARLOTTO, 2002) - constatação propagada com muita ênfase nos tempos atuais. Em contrapartida, vários estudos (Chechia; Andrade, 2005; Ribeiro; Andrade, 2006; Silveira; Wagner, 2012) apontam que a presença, a valorização e o envolvimento da família com a escola possibilitam melhorias nas relações interpessoais, no desempenho acadêmico dos alunos, na disciplina e no trabalho do professor.

A Síndrome de Burnout em professores atinge o ambiente educacional como um todo e dificulta o sucesso pedagógico. Esses profissionais são conduzidos a um processo de alienação, de desumanização e de apatia, responsável por problemas de saúde e consequente absenteísmo, que lhes incita a intenção de abandonar a profissão. O professor responsabiliza o ofício por seu malestar e sente grande arrependimento por ter escolhido a profissão.

Atualmente, a definição mais aceita do Burnout é a fundamentada na perspectiva social-psicológica de Maslach e colaboradores (CARLOTTO, 2002), e é composta de três dimensões: exaustão emocional, despersonalização e baixa realização pessoal no trabalho. A exaustão emocional pode ser definida como uma baixa energia e entusiasmo para o trabalho. A despersonalização, por sua vez, ocorre quando o profissional deixa de tratar como pessoa aqueles com quem se relaciona no trabalho e passa a coisificá-los. Já a baixa realização pessoal no trabalho se refere a uma análise depreciativa do próprio trabalho, vendo-se de forma negativa, como profissional. 
De um modo geral, a literatura aponta para várias formas de enfrentamento de situações estressantes. De acordo com Gil-Monte, Moriana-Elvira e HerruzoCabrere (1999 apud Carlotto e Camara, 2008), algumas formas de enfrentamento parecem ser mais eficientes que outras para evitar o aparecimento de Burnout. A capacidade de enfrentar uma situação estressante se refere às estratégias cognitivas e comportamentais que as pessoas frequentemente adotam para lidar com situações estressantes prolongadas. A autora cita que comumente são mais efetivas estratégias voltadas para a mudança da situação em si do que medidas que visem à fuga ou à negação do agente estressor.

Outra perspectiva que pode ser associada à Síndrome de Burnout é a da teoria da autoeficácia. Segundo Ferreira e Azzi (2010), a autoeficácia docente relaciona-se à crença que o professor tem na sua habilidade de realizar suas atividades e de atender aos objetivos propostos. Uma vez que a síndrome decorre, em parte, da descrença do profissional em relação ao seu ofício, pode-se associar, então, o surgimento da descrença à redução da autoeficácia do professor.

Sabe-se que o trabalho em si é fonte de desprazer, sofrimento e doença para qualquer trabalhador. Mas, de acordo com Dejours (1992 apud Ferreira e Azzi, 2010), uma vez que este possui uma autoeficácia e confia nas suas habilidades para atender às demandas de seu ofício, o trabalho passa a ser também fonte de realização pessoal e até mesmo de prazer para quem o realiza.

Ferreira e Azzi (2010) relatam os resultados de um estudo realizado por pesquisadores que investigaram a relação existente entre autoeficácia vinda do recebimento de suporte da direção e de outros professores no trabalho e os níveis de Burnout. O estudo mostra que há correlação negativa entre as variáveis, ou seja, quanto mais o professor se sente amparado por parte de diretores e colegas, menores são seus níveis de Burnout.

A figura do professor é central para que mudanças possam ser feitas na questão da saúde desse profissional. A leitura psicológica do conceito de autoeficácia, na teoria social cognitiva de Bandura (1997 apud Ferreira e Azzi, 2010), apresenta possibilidades de se desenvolver, nesse profissional, uma percepção pessoal de que é capaz de lidar com as situações adversas pessoais e ambientais e que é possível desenvolver estratégias de enfrentamento que lhe permitirão continuar sua trajetória (...).

É inegável a importância da profissão docente em uma sociedade letrada. A Síndrome de Burnout foi descrita pelos estudiosos por ter uma grande relevância social e merecer maior atenção das autoridades e da sociedade como um todo. Neste trabalho, espera-se justificar, com isso, uma maior contratação de psicólogos para auxiliarem os docentes no ambiente escolar.

\section{Conclusão}

A partir das pesquisas encontradas, constata-se que os professores, devido às dificuldades que estão enfrentando no cotidiano escolar, estão cada vez mais vulneráveis a problemas emocionais, físicos, esgotamento mental, desmotivação e apatia, prejudicando assim seu trabalho com os alunos e seu engajamento com a profissão. Muito se fala acerca da necessidade de professores multifuncionais e engajados efetivamente na transformação do contexto social e acadêmico deste país. Acredita-se que aliar a pedagogia e a psicologia na construção de um projeto educacional bemsucedido seria muito importante. O professor, protagonista na sala de aula, árbitro de tantos conflitos e divergências, precisa ser orientado sobre como lidar com seu próprio papel, com suas limitações e dificuldades.

Uma política pública que incluísse o psicólogo no contexto escolar traria benefícios não só para os professores, mas para toda a comunidade escolar, que ganharia em nível educacional e de aprendizagem. O trabalho constante e duradouro de um psicólogo preparado para lidar com professores que vivem nas condições apresentadas traria qualidade de vida e satisfação no exercício de uma carreira tão admirável e indispensável em qualquer âmbito da sociedade. Além disso, um auxílio nessa área seria capaz de promover melhoria no processo de ensino-aprendizagem, bem como de diminuir o número de faltas e a necessidade de licença médica por parte dos professores, em sua maior parte ocasionada por estresse e fadiga. Considerando que neste processo de acompanhamento psicológico aos docentes há a grande tendência de ajudá-los a lidar com os problemas por eles vividos, a educação, consequentemente, ganharia mais credibilidade, confiança e condição de transformação da realidade de todos nela envolvidos.

\section{ReferênCIAS}

ANSER, M. A. C.; JOLY, M. C. R.; VENDRAMINI, C. M M. Avaliação do conceito de violência no ambiente escolar: visão do professor. Psicologia: teoria e prática, São Paulo, n. 2, v.5, 2003. Disponível em: $<$ http://pepsic. bvsalud.org/scielo.php?pid=S1516$36872003000200007 \&$ script=sci_arttext>. Acesso em: 18 nov. 2014. 
CAMPOS, H. R. et al. Violência na escola: o psicólogo escolar na fronteira da política educacional. In: MARTínEZ, A. M. (org.). Psicologia escolar e compromisso social. Campinas: Alínea, 2005. p.32-46.

CARLOTTO, M. S. A síndrome de Burnout e o trabalho docente. Psicologia em Estudo, Maringá. 2002. Disponível em: <http://www.scielo.br/pdf/pe/v7n1/ v7n1a03.pdf>. Acesso em: 20 nov. 2014.

CARLOTTO, M. A.; CAMARA, S. G. Síndrome de Burnout e estratégias de enfrentamento em professores de escolas públicas e privadas. Psicologia da Educação, São Paulo, n. 26, jun. 2008. Disponível em: <http://pepsic. bvsalud.org/scielo.php?script=sci_arttext\&pid=S1414$69752008000100003 \&$ lng=pt\&nrm=iso $>$. Acesso em: 20 nov. 2014

CARRARO, P. R.; ANDRADE, A. dos S. O professor do ensino fundamental em grupos de reflexão. Revista MalEstar e Subjetividades, Fortaleza, v. 11, n. 4, p. 13391379, dez. 2011.

CHECHIA, V. A.; ANDRADE, A. dos S. O desempenho escolar dos filhos na percepção de pais de alunos com sucesso e insucesso escolar. Estudos de Psicologia, Natal, v. 10, n. 3, dez. 2005. Disponível em: <http://www.scielo. br/scielo.php?script=sci_arttext\&pid=\$1413-294X200500 0300012\&lng=pt\&nrm=iso>. Acesso em: 24 out. 2014.

CONSELHO REGIONAL DE PSICOLOGIA. Psicólogos (as) nas escolas. Projeto que insere Psicologia na rede pública de educação básica vai para CCJ. Publicado em 5/8/2013. Disponível em: <http://www.crpsp.org.br/portal/midia/ fiquedeolho_ver.aspx?id=647>. Acesso em: 10 out. de 2014.

FERREIRA, L. C. M.; AZZI, R. G. Docência, Burnout e considerações da teoria da auto-eficácia. Psicologia, Ensino \& Formação, Brasília, v. 1, n. 2, 2010. Disponível em: <http://pepsic.bvsalud.org/scielo.php?script=sci_ arttext\&pid=S2177-20612010000200003\&lng=pt\&nrm= iso>. Acesso em: 20 nov. 2014.

FONTANA, D. Psicologia para professores. São Paulo: Loyola, 1998.

GIONGO, C.; OLIVEIRA-MENEGOTTO, L. M. de. (Des) Enlaces da psicologia escolar na rede pública de ensino. Psicol. USP, 2010, v. 21, n. 4, 2010. Disponível em: <http://www.scielo.br/scielo.php?script=sci_ arttext\&pid=S0103-65642010000400011 >. Acesso em: 20 nov. 2014.
GUZZO, R. S. L. Escola amordaçada: compromisso do psicólogo com este contexto. In: MARTínEZ, A. M. (Org.). Psicologia escolar e compromisso social. Campinas: Alínea, 2005. p. 17-29.

GUZZO, R. S. L.; MEZZALIRA, A. S. da Costa; MOREIRA, A. P. G. Psicólogo na rede pública de educação: embates dentro e fora da própria profissão. Psicologia Escolar e Educacional, Maringá, v. 16, n. 2, dez. 2012. Disponível em: <http://www.scielo.br/scielo.php?script=sci_ arttext\&pid=S1413-85572012000200016\&lng=en\&nrm= iso>. Acesso em: 24 nov. 2014.

MARTínEZ, A. M. O psicólogo escolar e os processos de implantação de políticas públicas. In: CAMPOS, H. R. Formação em psicologia escolar: realidade e perspectivas. Campinas: Alínea, 2007. p. 110-133.

NEVES, M. M. B. da J. Queixas escolares: conceituação, discussão e modelo de atuação. In: GUZZO, R. S. L.; MARINHO-ARAÚJO, C. M. (Orgs.). Psicologia escolar: identificando e superando barreiras. Campinas: Alínea, 2011. p.172-192.

RIBEIRO, D. de F.; ANDRADE, A. dos S. A simetria na relação entre família e escola pública. Paidéia, Ribeirão Preto, v. 16, n. 35, dez. 2006. Disponível em: <http:// www.scielo.br/scielo.php?script=sci_arttext\&pid=S0103$863 \times 2006000300009 \& \mid n g=p t \& n r m=i s o>$. Acesso em: 21 nov. 2014.

SILVEIRA, L. M. de O. B.; WAGNER, A. A interação família-escola diante dos problemas de comportamento da criança: estudos de caso. Psicologia da educação, São Paulo, n. 35, dez. 2012. Disponível em: <http://pepsic. bvsalud.org/scielo.php?script=sci_arttext\&pid=S141469752012000200006\&lng=pt\&nrm=iso >. Acesso em: 24 nov. 2014.

TARNOWSKI, M.; CARLOTTO, M.. Síndrome de Burnout em estudantes de psicologia. Temas em psicologia, Ribeirão Preto, v. 15, n. 2, dez. 2007. Disponível em: $<$ http://pepsic.bvsalud.org/scielo.php?pid=S1413389X2007000200004\&script=sci_arttext $>$. Acesso em: 24 nov. 2014

VECTORE, C.; MAIMONI, E. H. A formação do psicólogo escolar e a atuação em instituições infantis. In: CAMPOS, H. R. Formação em psicologia escolar: realidade e perspectivas. Campinas: Alínea, 2007. p.135-147.

Recebido em: 07/04/2014

Aceito em: 17/11/2014 